\title{
Afterripening in curly mesquite seeds
}

\author{
ANDREW E. RALOWICZ AND CHARLES F. MANCINO
}

The authors are former graduate associate and assistant professor, Department of Plant Sciences, University of Arizona, Tucson 85721 .

\section{Abstract}

Curly mesquite (Hilaria belangeri Steud.) Nash) is a palatable nutritious range grass in the southwestern United States. Early research assumed no afterripening occurred in caryopses of this species and suggested that all seed could germinate immediately. Germination trials were conducted at 1, 6, 12, 18, 24, 30, and 36 weeks after harvest using seed cleaned either at harvest or just prior to each trial. Average increases in germination from 59 to $92 \%$ and 55 to $87 \%$ demonstrated an afterripening period of 12 weeks in seeds from 2 populations of curly mesquite. Maximum germinations of 94 and $90 \%$ occurred after 12 weeks for seeds cleaned at harvest and cleaned prior to each trial, respectively. Seeds not separated from fascicles at harvest displayed a rapid decline in total germination percentage after 24 weeks even though fascicles were removed just prior to germination trials. The extent and timing of the decline are greater if the fascicles are not removed prior to storage. Effects of the fascicle on germination remain unclear. Our findings suggest that seed storage periods and conditions should be taken into consideration when attempting to establish curly mesquite by seeding.

\section{Key Words: Hilaria belangeri (Steud.) Nash, germination, range} grass, Poacene

Curly mesquite (Hilaria belangeri (Steud.) Nash), an important native perennial range grass in Texas, New Mexico, and Arizona on heavily grazed areas (Humphrey 1960 , Gould 1981), has potential as a turfgrass in the Southwest (Kneebone 1985). A good understanding of the requirements for germination of curly mesquite caryopses (hereafter referred to as seed) is required before the full potential of this species can be realized. Little literature exists on germination of curly mesquite seed (Merrill and Young 1962, Kneebone 1985). Germination of cleaned seed (Merrill and Young 1962) and seed contained in fascicles (Merrill and Young 1962, Kneebone 1985) is generally less than 25\%. Merrill and Young (1962) suggested cleaned seed germinated immediately after harvest, but germination occurred only after 7.5 months for seed enclosed in fascicles. They concluded that dormancy resulted from the protective covering of the spikelet cluster rather than inhibitors. Data from Merrill and Young (1962) and from our laboratory suggest germination percentages of cleaned seed increase with storage, suggesting an afterripening requirement for optimum germination. The purpose of this study was to quantify the effect of seed age and fascicle removal on germination of curly mesquite seed.

\section{Materials and Methods}

Two different populations of curly mesquite were grown at the

The authors wish to acknowledge the financial input of the United States Golf Association and the assistance of the SCS Plant Materials Center (Tucson, Arizona), the Arizona Crop Improvement Association (Tucson, Arizona), and Dr. R. Kuehl (UA Experiment Station statistician).

Paper 7303 of Arizona Agricultural Experiment Station.

Manuscript accepted 13 April 1991.
University of Arizona Campus Agricultural Center (Tucson) in 1989. Both populations were grown on a sandy loam soil (Typic Torrifluvent) with sprinkler irrigation. Population I consisted of 90 2-year old swards. Population I plants were collected from 30 geographically separate sites on southern Arizona rangeland and transplanted into the field in 1988. Seed harvested from Population I in 1988 and sown in 1989 produced the plants of Population II.

Mature spikes were bulk harvested separately from each population on 1 Dec. 1989. One half of each seed lot was manually cleaned on a rubbing board on 5 Dec. 1989. The other half of each seed lot remained in the fascicle. Seeds, randomly counted and sorted in advance into replications of seed treatments for each storage period, were stored at room temperature in paper envelopes or bags, respectively, for the duration of the experiment. Sufficient fascicles were allocated to replications to insure 80 whole seed after cleaning. No specific size criteria were used in the selection of seed, only that whole seeds were used. Fungal problems were never apparent during storage of cleaned seed or seed not separated from fascicles.

Germination trials on cleaned seed began 11 Dec. 1989 and were conducted at 6-week intervals for 36 weeks until seed lots were depleted. The experiment used a completely randomized, split plot design with storage period serving as main plots, and seed treatments as subplots. Seed treatments consisting of initially cleaned (IC, cleaned at harvest) and freshly cleaned (FC, cleaned prior to each trial) seed from both populations were independently randomized within each of the 5 replications per trial. Germination trials were independently randomized. Seed $(80$ per $100 \times 15 \mathrm{~mm}$ dish) were imbibed in petri dishes containing filter paper moistened with $6 \mathrm{ml}$ of distilled deionized water, and sealed with a strip of parafilm. Seeds were incubated in a controlled environment with 12-hour cycles of $35^{\circ} \mathrm{C} / 23^{\circ} \mathrm{C}$ and constant illumination (J.A. Young, 1988, personal communication). The same environmental chamber was used for each trial.

A seed was considered germinated when the radicle and coleoptile were at least $1-\mathrm{mm}$ long. Germination data were collected after 48 and 96 hours. Germination trials were terminated after 96 hours as the remaining caryopses were no longer viable. Populations were analyzed separately due to differing field environments with respect to methods of establishment and plant densities, irrigation regimes, and a minor difference in soil texture. Analysis of variance and LSD tests were performed on arcsin transformed percentage data (Snedecor and Cochran 1980). The main plot factor of storage period was tested with the mean square error term of replications within storage period. Regression analysis and generation of the equations of best fit were performed with SPSS. Values presented in the text are untransformed means.

\section{Results}

Analysis of variance showed a highly significant $(P<0.01)$ storage period $X$ seed treatment interaction for each population. Tests or significance between seed treatment means were conducted 


\section{Population I}

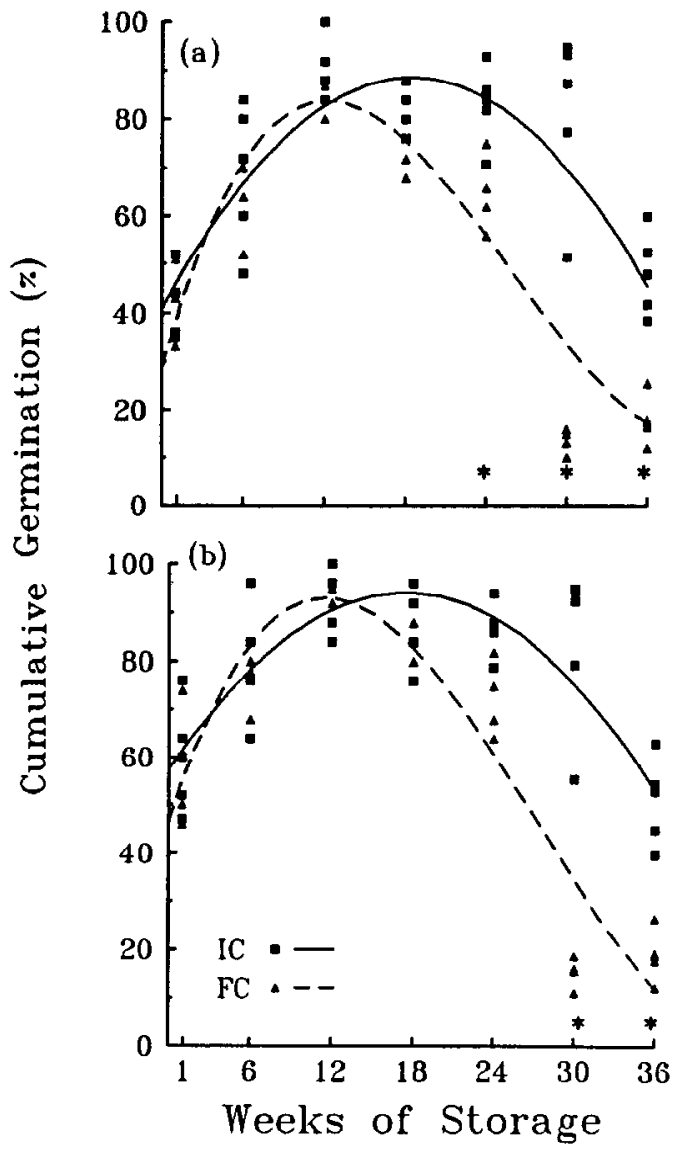

Fig. 1. Relationship between germination and storage period for curly mesquite seed from Population I. Seed treatments were initially cleaned (IC, seed cleaned at harvest) and freshly cleaned (FC, seed cleaned prior to each trial), (a) cumulative germination after 48 hours $\left(\hat{\mathbf{y}}_{1 C}=40.89+\right.$ $\left.5.17 x-0.14 x^{2}, \hat{y}_{F C}=28.71+10.06 x-0.54 x^{2}+0.007 x^{3}\right) ;(b)$ cumulative germination after 96 hours $\left(\hat{\mathrm{y}}_{\mathrm{FC}}=57.41+4.2 \mathrm{x}-0.12 \mathrm{x}^{2}, \hat{\mathrm{y}}_{\mathrm{IC}}=46.45+8.9 \mathrm{x}\right.$ $\left.-0.49 x^{2}+0.006 x^{3}\right)$ where $x=$ weeks of storage and $y=$ percent germination. Asterisk ( $\left.{ }^{*}\right)$ above a storage period denotes significance $(P<0.05)$ between seed treatments.

within storage periods.

\section{Population I}

Aging of seed significantly $(P<0.05)$ influenced germination within each seed treatment after $\mathbf{4 8}$ hours (Fig. 1a). Seed cleaning significantly $(P<0.05)$ affected germination after 48 hours from 24 to 36 weeks.

Total germination percentages ( 96 hours) began to increase after 6 weeks and peaked after 12 weeks based on the actual data points (Fig. 1b). This demonstrates that an afterripening period exists in curly mesquite seed, but that only a short period is required to significantly improve total germination percentage. Seed cleaning did not significantly affect total germination percentages of Population I until 30 and 36 weeks of storage (Fig. 1b). Germination in FC seed declined from $75 \%$ at 24 weeks to $15 \%$ after 30 weeks, whereas germination of IC seed decreased from $87 \%$ at 24 weeks to $83 \%$ at 30 weeks to $51 \%$ after 36 weeks.

\section{Population II}

Germination after 48 and 96 hours was significantly $(P<0.05)$ affected by length of storage period (Fig. $2 a$ and $2 \mathrm{~b}$ ). Responses were cubic with the exception of IC seed after 96 hours which was quadratic. Total germination began to significantly $(P<0.05)$
Population II
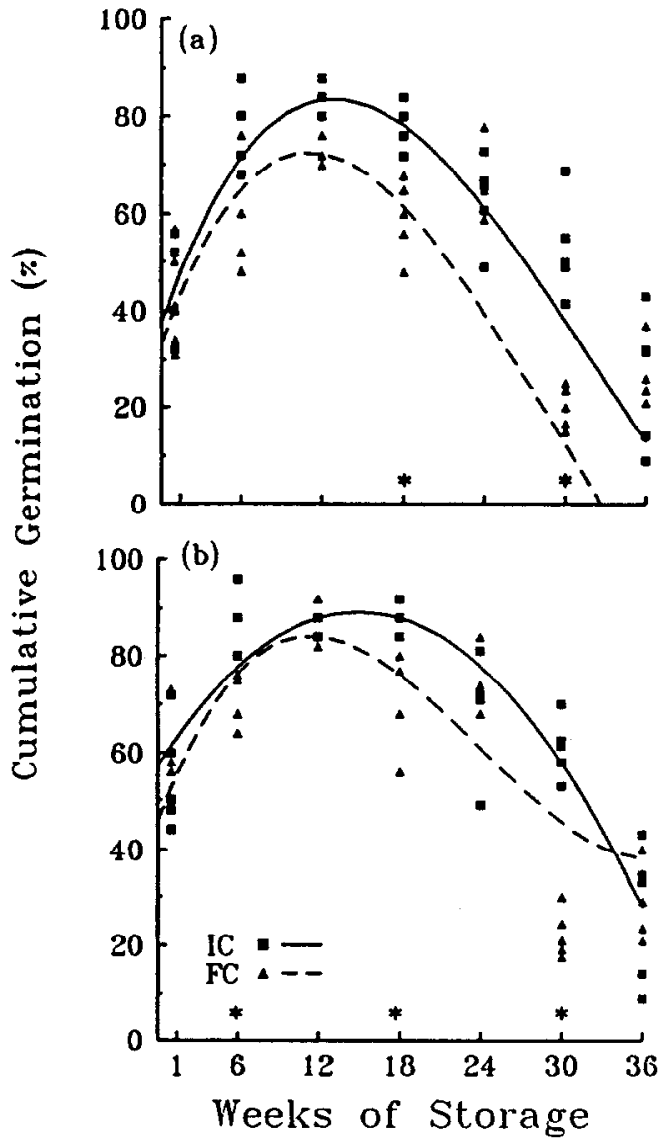

Fig. 2. Relationship between germination and storage period for curly mesquite seed from Population II. Seed treatments were initially cleaned (IC, seed cleaned at harvest) and freshly cleaned (FC, seed cleaned prior to each trial). (a) cumulative germination after 48 hours $\left(\hat{y}_{\text {IC }}=37.3+\right.$ $\left.7.82 x-0.38 x^{2},+0.004 x^{3}, \hat{y}_{F C}=32.2+7.7 x-0.43 x^{2}+0.005 x^{3}\right) ;(b)$ cumulative germination after 96 hours $\left(\hat{y}_{1 C}=57.39+4.22 x-0.14 x^{2}, \hat{y}_{F C}\right.$ $\left.=45.6+7.5 x-0.43 x^{2}+0.006 x^{3}\right)$ where $x=$ weeks of storage and $y=$ percent germination. Asterisk (*) above a storage period denotes significance $(P<0.05)$ between seed treatments.

increase after 6 weeks. Differences in total germination between seed treatments occurred at 6,18, and 30 weeks. Maximum germination of IC seed occurred during 6 to 18 weeks of storage and at 12 weeks for FC seed. Total germination percentages of FC seed rapidly declined after 24 weeks.

\section{Discussion}

For each storage period, most of the germination occurred within $\mathbf{4 8}$ hours regardless of seed source. Over all storage periods and populations, germination of IC seed averaged $91 \%$ of the total after 48 hours and FC seed averaged $86 \%$. This information is important when considering time of seeding. High soil temperatures and timely rainfalls may be requirements for rapid germination and successful establishment of curly mesquite.

Responses of curly mesquite seed to length of storage period and seed treatments were similar for both populations. Seed produced in southern Arizona required 12 weeks of afterripening at room temperature in unsealed containers for maximum germination. Afterripening has been observed in other grass species: wild oats (Avena fatua) (Toole and Coffman 1940, Laude 1956), side-oats grama (Bouteloa curtipendula) (Shaidaee et al. 1969), and several species within the genera Bromus and Hordeum (Laude 1956). 
The major difference between seed cleaning treatments was the magnitude of decline in germination percentage with the longer storage periods. Seed germination declined after 30 weeks of storage. The extent and timing of the decline is greater if fascicles are not removed prior to storage. These results warrant investigation into the effects of the fascicle on declining germination of curly mesquite seed. A better understanding of this phenomenon could extend viability of stored seed.

\section{Literature Cited}

Gould, F.W. 1981. Grasses of southwestern United States. The Univ. of Arizona Press, Tucson, Ariz. p. 158-160.

Humphrey, R.R. 1960. Arizona range grasses-their description, forage value, and management. Univ. of Arizona Agr. Exp. Sta. Bull. 298:57-60.
Kneebone, W.R. 1985. Hilaria belangeri, a rediscovered potential low maintenance arid land turf. p. 285-288. In: F. Lemaire (ed.) Proc. Sth Int. Turfgrass Res. Conf. Avignon, France. 1-5 July 1985. INRA Publ. Paris, France.

Laude, H.M. 1956. Germination of freshly harvested seed of some western range species. J. Range Manage. 9:126-129.

Merrill, L.B., and V.A. Young. 1962. Germination and root establishment in curly mesquitegrass. Texas Agr. Exp. Sta. MP-615. p. 1-6.

Shaidace, G., B.E. Dahl, R.M. Hansen. 1969. Germination and emergence of different aged seeds of six grasses. J. Range Manage. 22:240-243.

Snedecor, G.W., and W.C. Cochran. 1980. Statistical methods. The Iowa State Univ. Press.

Toole, E.H., and F.A. Coffman. 1940. Variations in the dormancy of seeds of the wild oat, Avena fatua. J. Amer. Soc. Agron. 32:631-638. 